super-dense stars remain a mystery, but their structure is dictated by the same littleunderstood interaction that creates bizarre phenomena in neutron-rich nuclei. "One of the reasons understanding neutron skins and halos is so important is to make the most of astrophysical observations," says Panagiota Papakonstantinou, a nuclear physicist at the Institute for Basic Science in Daejeon, South Korea.

Obertelli and his collaborators hope to create a trap that can store a record 1 billion antiprotons - more than 100 times as many as can be stored in any existing experiment. Another difficulty will be keeping the particles for weeks at a time, something that has so far been achieved for no more than a few dozen antiparticles at once. This will mean storing them at 4 degrees above absolute zero, and in a vacuum comparable with that of intergalactic space. "It's a challenging project," says Chloé Malbrunot, an antimatter physicist at CERN. "But I do think it is feasible."

Developing and testing technology for the portable trap will take around four years, with the first measurements scheduled for 2022. If the method works, physicists could transport antimatter much farther afield, allowing other scientists who aren't involved in the six experiments huddled at CERN's antiproton source to study and use the elusive matter.

"As soon as they can demonstrate one billion protons and keep them for several weeks, then many more experiments will join, and people with new ideas will come," says Malbrunot. "I think it will really open up the field." -

\title{
Sensor array provides new look at global ocean current
}

\section{Findings hint at the complexity of North Atlantic currents that drive the world's weather.}

\section{峑}

BY JEFF TOLLEFSON The North Atlantic Ocean is a major driver of the global currents that regulate Earth's climate, mix the oceans and sequester carbon from the atmosphere - but researchers haven't been able to get a good look at its inner workings until now. The first results from an array of sensors strung across this region reveal that things are much more complicated than scientists previously believed.

Some research suggests that climate change is slowing currents in this area, which could affect weather and oceans around the world. Scientists with the Overturning in the Subpolar North Atlantic Program (OSNAP) are closer to pinning this down now. With data collected from 2014 to 2016, researchers have found that the strength of the Atlantic meridional overturning circulation - which pumps warm surface water north and returns colder water at depth - varies with the winds and the seasons, transporting an average of about 15.3 million cubic metres of water per second. The team presented its findings last week at an ocean-sciences meeting in Portland, Oregon.

The measurements are similar in magnitude to those from an array called RAPID, which has been operating between Florida and the Canary Islands since 2004. But scientists say they were surprised by how much the currents measured by the OSNAP array varied over the course of two years.

"We're delighted with the data," says Susan Lozier, an oceanographer at Duke University in Durham, North Carolina who is coordinating OSNAP. "We always find more

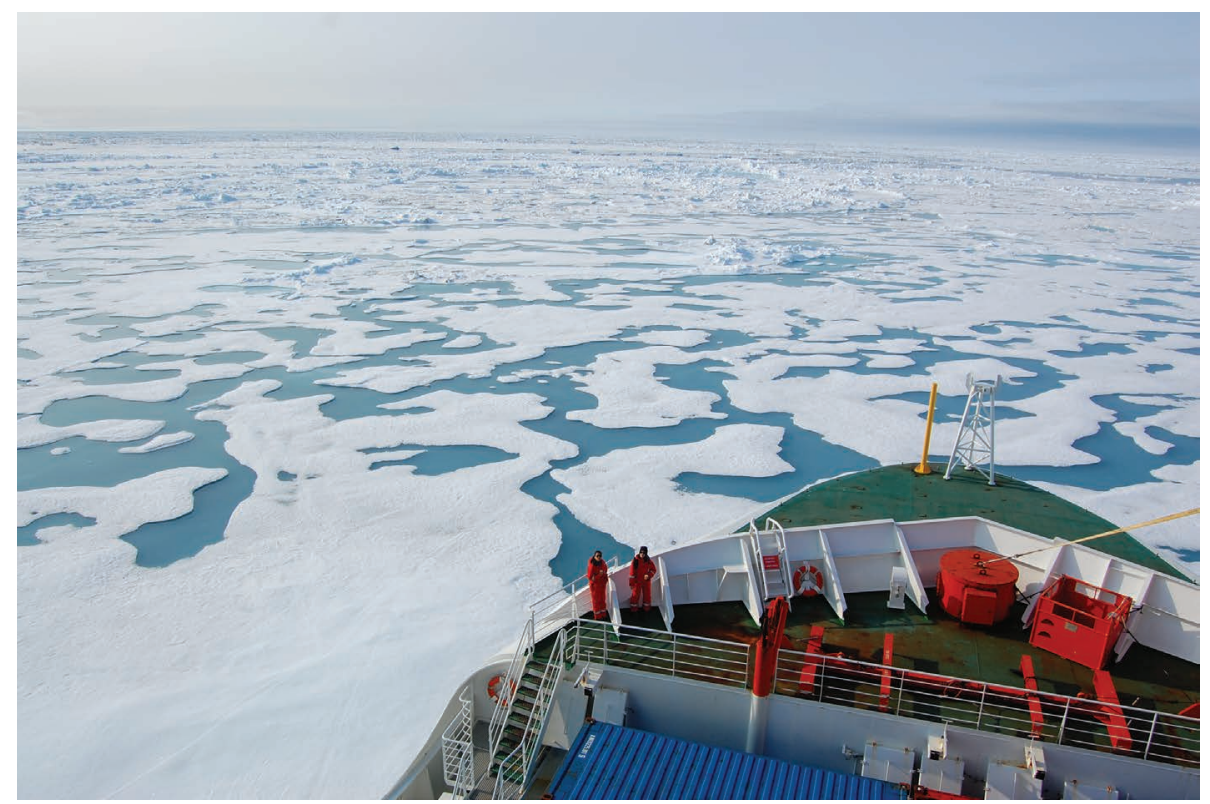

The research vessel Polarstern makes its way through sea ice off eastern Greenland.

complexity and more variability, but perhaps that shouldn't be surprising given how undersampled the ocean is."

OSNAP includes 53 moorings festooned with instruments that measure water conditions including temperature, salinity and current speeds. The network extends from southern Labrador in Canada to the southern tip of Greenland and on to the Rockall Trough off the west coast of Scotland (see 'Sea sensors'). And it's positioned where surface waters travelling north begin to cool and sink into the deep sea before turning south towards the Equator.
The array was designed to help answer fundamental questions about what drives this overturning circulation, which transports heat from the tropics to the poles. Climate models suggest that the formation of cold, deep water in the north might slow down as the climate warms. This would affect weather patterns in northern Europe and beyond, and some research suggests that this process could already be under way (S. Rahmstorf et al. Nature Clim. Change 5, 475-480; 2015).

The RAPID array has registered a decline in the strength of this overturning circulation since 2008, including a $30 \%$ drop 


\section{SEA SENSORS}

Instruments placed across the North Atlantic are starting to reveal the inner workings of a global current that mixes the oceans.

Warmer surface currents $\square$ Cold and dense deep water Cold water from the Arctic

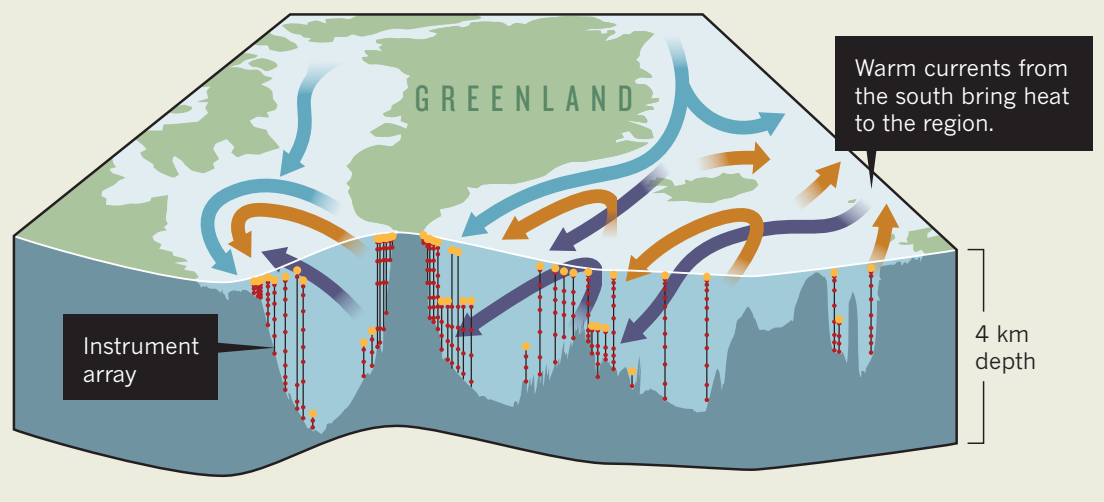

from 2009 into 2010. A study published in Geophysical Research Letters on 12 February suggests that this slowdown is part of a longer-term pattern of climate variability across the north Atlantic, and not caused by global warming (D. A. Smeed et al. Geophys. Res. Lett. http://doi.org/cknk; 2018). Teasing a potential climate-change signal out of the data could take time, in part because the natural swings in the system are so large, says lead author David Smeed, an oceanographer at the National Oceanography Centre in Southampton, UK, who is involved with RAPID.

Researchers can't fully understand this slowdown without knowing what's happening in the North Atlantic, which drives the system. OSNAP is starting to fill in that knowledge gap.

Lozier hopes that the array will eventually settle a long-standing question about what powers this system of currents: how much of the overturning circulation is driven by the winds and how much by the formation of cold, dense water that sinks into the deep sea.

Since the array started collecting data, the North Atlantic has experienced two cold winters in a row. The data indicate that the ocean formed a lot of chilly water as a result. But it remains unclear to what extent this actually had an impact on the strength of the overturning circulation.

Eventually, Lozier wants to see how the overturning circulation responds during a warmer winter that produces less cold water in the region. "We just need to keep measuring," she says.

\section{CRISPR hack transforms cells into data recorders}

\section{Gene-editing tool can be harnessed to give a close-up view of life's most basic processes.}

\section{BY HEIDI LEDFORD}

$\mathrm{R}$ esearchers have harnessed the popular gene-editing tool CRISPR-Cas9 to turn DNA into a sensitive recording device. The recorder can document the duration and order of events within cells - and even erase and re-record information in the same genome.

The work, published in Science on 15 February $^{1}$, joins a flock of other CRISPRbased cellular recorders that have emerged from research labs over the past few years. The hope is that such recorders could keep track of changes in gene expression, trace a cell's individual family lineage or monitor shifts in environmental conditions.

"It's clear that the genome has this enormous recording capacity," says Jan Philipp Junker, a systems biologist at the Max Delbrück Center for Molecular Medicine in Berlin. "With CRISPR, we finally have the tools to use it."

It is one of many ways in which researchers are tinkering with the machinery of CRISPRCas9 to forge new types of molecular tool. Two papers also published in Science on 15 February describe how CRISPR can be used to detect disease-causing viruses ${ }^{2,3}$.

The inspiration for the cellular recorders was the flight-data recorder found in many aeroplanes, says chemical biologist David Liu of the Broad Institute of MIT and Harvard in Cambridge, Massachusetts. "Just like a flightdata recorder records events that happen to an airplane, the cell-data recorders can be used to monitor stimuli that the cell is exposed to, or changes in the cell signalling," he says.

Researchers typically use CRISPR-Cas9 to alter DNA sequences by directing the Cas9 enzyme to cut DNA at a site dictated by the
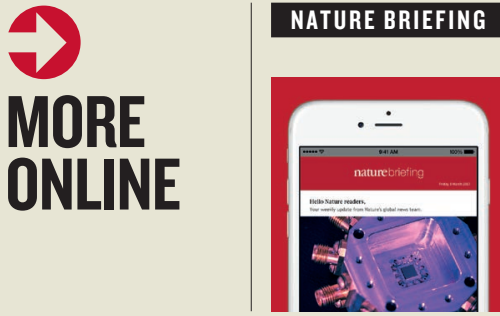

\section{NEWS}

Save time - get the daily Nature newsletter free in your inbox go.nature. com/2cxbubr
- Household chemicals such as soaps, paint and perfumes rival vehicles as a smog source go.nature.com/2hwr052

- Ocean tides could have driven ancient fish to walk go.nature.com/2gqfzwf

\section{NATURE PODCAST}

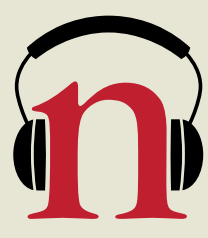

Defining adolescence; high-school researchers; and the science of teen risk taking nature. com/nature/podcast 